\title{
Deprescribing: a new word to guide medication review
}

\author{
Christopher Frank MD
}

See related cases by Farrell and colleagues at www.cmaj.ca/lookup/doi/10.1503/cmaj.122012 (Oct. 1 issue) and www.cmaj.ca/lookup/doi/10.1503 /cmaj.130523 (page 445, this issue)

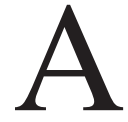

literature search on optimizing medications will yield a number of peerreviewed articles containing the term "deprescribing." Although use of the term dates back to $2003,{ }^{1}$ it did not appear in CMAJ until recently, in a news article ${ }^{2}$ announcing the award of a grant supporting an initiative led by Barbara Farrell, a pharmacist and scientist with the Bruyère Research Institute. Farrell is developing clinical guidelines to facilitate deprescribing and help physicians determine whether patients are taking medications that they no longer need or that should be reduced in dosage. She is also the lead author on a series of case-based practice articles on polypharmacy published in CMAJ.,4 But does this mean we will be faced with yet another set of clinical practice guidelines, this time to guide us through the challenges of appropriate prescribing for frail older adults, which may be greeted with skepticism by some?

Use of multiple medications increases the risk of adverse drug reactions (13\% among patients taking five medications v. $6 \%$ among those taking one to two) and of nonadherence among older patients in Canada. ${ }^{5}$ Studies have reported that more than $50 \%$ of older adults in institutions and $27 \%$ of those living in the community are taking more than five prescribed medications daily.6. ${ }^{5,6}$ The proportion increases with age. ${ }^{7}$ Despite the complexity of medication lists for many patients, less than half of older Canadians with chronic conditions reported having their medications reviewed by a physician $(48 \%)$ or having the potential adverse reactions explained to them. ${ }^{6}$ Only $28 \%$ of older adults reported receiving help, at least some of the time, in making a treatment plan, and $48 \%$ reported talking to a health professional about their treatment goals. ${ }^{6}$ Having clear discussions with patients is one of the best strategies a physician can have to avoid polypharmacy, but it can be time-consuming.

Although "polypharmacy" is often defined by the total number of medications a person is taking (typically more than four or five $e^{8}$ ), applying a simple cutoff number is problematic for several reasons. Sometimes multiple medications are necessary to improve function, control symptoms, limit disease progression or extend life. Reducing the number to below a certain cutoff may result in underprescribing, which means medications that should be considered are not prescribed and important conditions may be undertreated. An example is not considering prescribing a bisphosphonate after hip fracture in a person who has a reasonable prognosis and no contraindications only because he or she is already taking many other medications. "Polypharmacy" can sometimes have almost derogatory connotations, which leaves physicians reluctant to add to an already long list of treatments. Patients who have more comorbid medical conditions are the most likely to experience underprescribing for this reason. Older adults may have a reasonable indication for each medication on the list. However, these indications will change over time as the patients' function, health and goals of care change. Ongoing review of the multiple prescriptions is needed.

A physician should consider deprescribing whenever he or she does a critical review to optimize a medication list. Deprescribing requires a shift in choice of clinical outcomes and in the process of prescribing medications for frail older patients. In 2005, Boyd and colleagues diligently applied clinical practice guidelines to a fictitious case of a 79-year-old patient with several common chronic diseases and showed that following the guidelines could result in the prescription of 12 medications with uncertain outcomes for the patient. ${ }^{9}$ Six of the medications had a prevention
Competing interests: None declared.

This article was solicited and has not been peer reviewed.

Correspondence to: Christopher Frank frankc@providencecare.ca

CMAJ 2014. DOI:10.1503 /cmaj.131568 
focus rather than a clear functional benefit, which may not have been relevant for the person. A large increase in the use of medications for prevention in older patients has been observed in a study of prescribing trends in Canada.

Boyd and colleagues' study shows how the use of disease-specific targets and outcomes may increase medication numbers and adverse drug reactions. As an alternative, Fried and colleagues proposed targeting "universal outcomes" to facilitate discussions with patients about balancing the relative importance of improving symptoms, increasing longevity, and improving function and independence..$^{10}$ Consideration of such outcomes may assist with choosing medications to add or withdraw when patients have multiple comorbidities or have limited function or prognosis. Preventive medications such as statins may pose the biggest challenge.

Deprescribing is an active review process that prompts the physician to consider which medications have lost their advantage in the risk-benefit trade-off, especially in patients with changing goals of care or limited life expectancy. The first step is to discuss universal outcomes and goals of care with the patient and to give information about the evidence of benefit of questionable medications the patient is taking. Not prescribing a preventive medication that likely offers little benefit for a frail patient may be easier than withdrawing one that has been taken for years. Considering deprescribing encourages physicians to discuss with patients the role and benefits of their medications and to collaborate with them on decisions to try to discontinue medications. This, in turn, can lead to discussions about broader goals of care and caregiving plans.

Medication review and optimization should ideally involve other health professionals. Hospital, clinic and community nurses can play an important role in assisting patients with adherence and in clarifying the accuracy of a medication list. Collaboration with clinical pharmacists has been shown to be an important strategy to reduce inappropriate medications and to help deprescribe as appropriate. Published models include "pharmaceutical detailing" by a pharmacist and facilitated medication review for patients in the community, in hospital and in long-term care facilities. Computerized decision supports may also be helpful. ${ }^{8}$

Tools beyond clinical practice guidelines are available to support physicians with deprescribing. ${ }^{11,12}$ The US campaign Choosing Wisely includes lists created by specialty societies of "Five Things Physicians and Patients Should Question," which are designed to help physicians and patients engage in conversations about unnecessary tests, treatments and procedures. For example, in the American Geriatrics Society's list, physicians are advised to "avoid using medications to achieve hemoglobin A1c $<7.5 \%$ in most adults age 65 and older; moderate control is generally better" (www.choosingwisely.org /doctor-patient-lists/american-geriatrics-society). This guidance may result in a lower incidence of hypoglycemia from medications and decrease potential adverse effects such as nausea, anorexia and fluid retention, which could exacerbate heart failure. (In Canada, a similar campaign called Choosing Wisely Canada is being launched in April 2014, www.choosingwiselycanada.org.)

The CMAJ series of case-based articles on polypharmacy by Farrell and colleagues illustrate well the importance of regular medication review, identification of adverse drug reactions, attention to comorbidities and other medications, and monitoring of the effects of new medications. ${ }^{3,4}$ Given the risks associated with multiple medications in older patients, it is crucial that we take on these tasks in collaboration with our patients, their families and other health professionals.

\section{References}

1. Woodward M. Deprescribing: achieving better health outcomes for older people through reducing medications. J Pharm Pract Res 2003;33:323-8.

2. Cross C. Introducing deprescribing into culture of medication. CMAJ 2013; 185:E606.

3. Farrell B, French Merkley V, Thompson W. Managing polypharmacy in a 77-year-old woman with multiple prescribers. CMAJ 2013;185:1240-5

4. Farrell B, Monahan A, Thompson W. Revisiting medication use in a frail 93-year-old man experiencing possible adverse effects. CMAJ 2014;186:445-9.

5. Ramage-Morin PL. Medication use among senior Canadians. Health Rep 2009;20:37-44.

6. Reason B, Terner M, Moses MA, et al. The impact of polypharmacy on the health of Canadian seniors. Fam Pract 2012;29: 427-32.

7. Bajcar JM, Wang L, Moineddin R, et al. From pharmaco-therapy to pharmaco-prevention: trends in prescribing to older adults in Ontario, Canada, 1997-2006. BMC Fam Pract 2010;11:75.

8. Patterson SM, Hughes C, Kerse N, et al. Interventions to improve the appropriate use of polypharmacy for older people. Cochrane Database Syst Rev 2012;5:CD008165.

9. Boyd CM, Darer J, Boult C, et al. Clinical practice guidelines and quality of care for older patients with multiple comorbid diseases: implications for pay for performance. JAMA 2005;294: 716-24.

10. Fried TR, Tinetti M, Agostini J, et al. Health outcome prioritization to elicit preferences of older persons with multiple health conditions. Patient Educ Couns 2011;83:278-82.

11. Beers MH, Ouslander JG, Rollingher I, et al. Explicit criteria for determining inappropriate medication use in nursing home residents. UCLA Division of Geriatric Medicine. Arch Intern Med 1991;151:1825-32.

12. Gallagher P, Ryan C, Byrne S, et al. STOPP (Screening Tool of Older Person's Prescriptions) and START (Screening Tool to Alert doctors to Right Treatment). Consensus validation. Int J Clin Pharmacol Ther 2008;46:72-83.

Affiliation: Department of Medicine, Queen's University, Kingston, Ont. 